\title{
Transcatheter Closure of Residual Atrial Septal Defect Following Implantation of Buttoned Device
}

\author{
Rolando Zamora, MD, Daniela Lax, MD, Richard L. Donnerstein, MD, and Thomas R. Lloyd, MD

\begin{abstract}
We report a case in which residual shunting after a buttoned device occlusion of atrial septal defect (ASD) was eliminated by transcatheter retrieval of a portion of the device, followed by implantation of a second device. This method may be helpful for those patients with residual ASDs who decline surgical device retrleval and defect closure.

(c) 1995 Wiley-Liss, Inc.
\end{abstract}

Key words: Left to right shunt

\section{INTRODUCTION}

Residual left-to-right shunting is common after transcatheter occlusion procedures for secundum ASD [1-3] but has usually been of minor degree with a clear tendency to spontaneous resolution. Significant residual shunts following device closure of patent ductus arteriosus have been successfully closed by application of additional devices [4.5], but this strategy has not been applied to ASD occlusion. We report a case in which significant residual shunting after buttoned device occlusion of ASD was successfully eliminated by transcatheter retrieval of a portion of the implanted device, followed by implantation of a second buttoned device.

\section{CASE REPORT}

The patient was a white female who first underwent transcatheter closure of ASD at 23 months of age. At that time she weighed $10.3 \mathrm{~kg}$ and her ratio of pulmonary to systemic blood flow was 2.5: I by oximetry. The balloon occlusion diameter [6] of her defect was $18 \mathrm{~mm}$. A buttoned device (Custom Medical Devices, Amarillo, TX) of $35 \mathrm{~mm}$ diagonal dimension was implanted using transthoracic echocardiographic guidance. Oximetric measurements after implantation indicated a pulmonary to systemic blood flow ratio of 1.5:1. Pulmonary arteriography confirmed a moderate residual shunt, as did echocardiography. Since it had been our experience that small residual shunts had a tendency to spontaneous resolution [2], we hoped that with time her shunt would decrease. At 1 month follow-up, echocardiography showed a smaller residual shunt, with normal interventricular septal motion and right ventricular size. An arm of the occluder was noted to extend through the defect into the right atrial cavity, with the opposite arm projecting into the left atrial cavity. At 6-month follow-up, device position was unchanged by radiography and echocardiography, but the volume of residual shunting had greatly increased, as evidenced by echocardiographic right ventricular enlargement and flat interventricular septal motion, as well as by return of the systolic murmur and widely split second heart sound. At this point, surgical device retrieval and repair of ASD [7] was offered to the family, but they declined. No further clinical, radiographic, or echocardiographic changes were noted over a total of 22 months of follow-up. At the age of 45 months (weight $14 \mathrm{~kg}$ ), a transcatheter attempt at correction of device position was offered, with the possibility of device retrieval and/or placement of a new device if repositioning failed. This procedure was undertaken after obtaining informed consent from the patient's parents under a protocol approved by the Human Subjects Committee of the University of Arizona.

The procedure was performed under general anesthesia using transesophageal echocardiographic guidance. The ratio of pulmonary to systemic blood flow by oximetry was 2.8:1. A $35 \mathrm{~mm}$ Amplatz goose-neck snare (Microvena Corp., White Bear Lake, MN) was advanced to the right atrium to snare the distal end of the occluder arm protruding into the right atrium. This arm was then manipulated across the ASD. Upon release, the device

From the Steele Memorial Children's Research Center, University Heart Center and Department of Pediatrics (Cardiology), University of Arizona, Tucson, and Division of Pediatric Cardiology, Department of Pediatrics, C.S. Mott Children's Hospital, University of Michigan, Ann Arbor.

Received January 9, 1995; revision accepted April 20, 1995.

Address reprint requests to Rolando Zamora. M.D., University of Arizona, Department of Pediatrics, 1501 N. Campbell Avenue, Tucson, AZ 85724. 


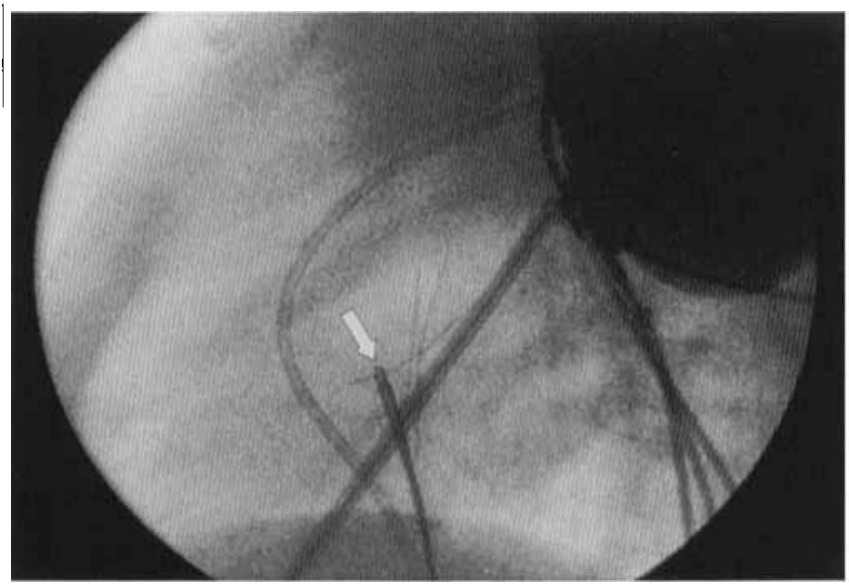

Fig. 1. The arrow points to the snare grasping the protruding occluder arm before traction is applied.

immediately returned to its original position. This maneuver was repeated several times with the same result. An attempt was then made to retrieve the device. The snare was used to grasp the protruding occluder arm as near as possible to the center of the occluder (Fig. 1). When traction was placed on the device, the device would not separate from the atrial septum, even when the device and atrial septum were pulled near the orifice of the inferior vena cava. With further traction, the arm that had been grasped by the snare separated from the device, including the wire whose ends formed the skeleton of the arms protruding into the right and left atrial cavities. These portions of the device remained attached to the snare and were easily removed through the femoral venous sheath (Fig. 2).

Transesophageal echocardiography showed that the polyurethane foam portion of the arm that had previously projected into the left atrial cavity had spontaneously retracted to the remainder of the occluder, presenting no barrier to proper placement of a second buttoned device. The diameter of the residual defect was $9 \mathrm{~mm}$ by echocardiography; balloon sizing was not attempted because of concerns about dislodging foam from the skeleton of the original device. A $30 \mathrm{~mm}$ buttoned device was advanced to the left atrium through an 8 French Mullins sheath, and correct deployment against the atrial septum was confirmed by echocardiography (Fig. 3). However, when the counteroccluder was advanced, the distal arm was inadvertently directed across the defect, resulting in an unstable device position after buttoning (Fig. 3). The misdirected counteroccluder arm did not project into the atrial cavity and thus did not interfere with apposition of the near device to the atrial septum, as had the previously retrieved occluder arms. Therefore, a second counteroccluder was then advanced to the proper location in the right atrium and buttoned in series with

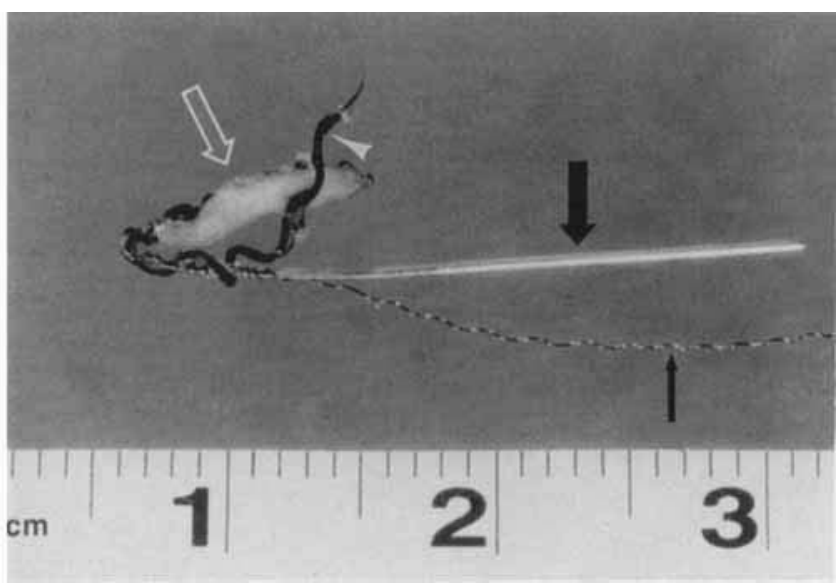

Fig. 2. The retrieved occluder arm is shown. The large black arrow points to the core of the wire that formed the skeleton of the arms formerly protruding into the left and right atrial cavities. Note the outer spring portion of the wire, which has unraveled (small black arrow). The white arrow shows the polyurethane foam from the tip of the arm formerly protruding into the right atrial cavity. Note the thorough endothelial coverage of this arm despite its lack of contact with the endocardlum. The arrowhead points to the suture that secured the wire skeleton to the polyurethane foam.

the first counteroccluder, securing device position. After release of this device, six segments of wire skeleton can be seen radiographically (Fig. 4): three on the left atrial side of the septum (one remaining in the original occluder and two in the new occluder), two on the right atrial side (the original counteroccluder and the second new counteroccluder), and one obliquely crossing the ASD (the first new counteroccluder). No left-to-right shunt could be detected by oximetry, although angiography and color flow Doppler echocardiography detected trivial residual shunting. Transthoracic echocardiography confirmed complete resolution of the residual shunting 1 day following the procedure. At 2 months follow-up, radiographic and echocardiographic device position remains unchanged, with no detectable residual shunt (Fig. 5). There has been no clinical evidence of systemic or pulmonary thromboembolism.

\section{DISCUSSION}

Clinically significant residual shunting is not a common problem after transcatheter occlusion of ASDs with the buttoned device. Of 166 cases of successful device implantation reported, only six required operation for residual shunt, recurrent neurologic symptoms, atrial perforation, or wire distortion [3]. The present case was the sole patient with persistent residual shunting of $\geq$ moderate severity in either U.S. [2] or international [3] trials of the buttoned device. The residual shunt in this 

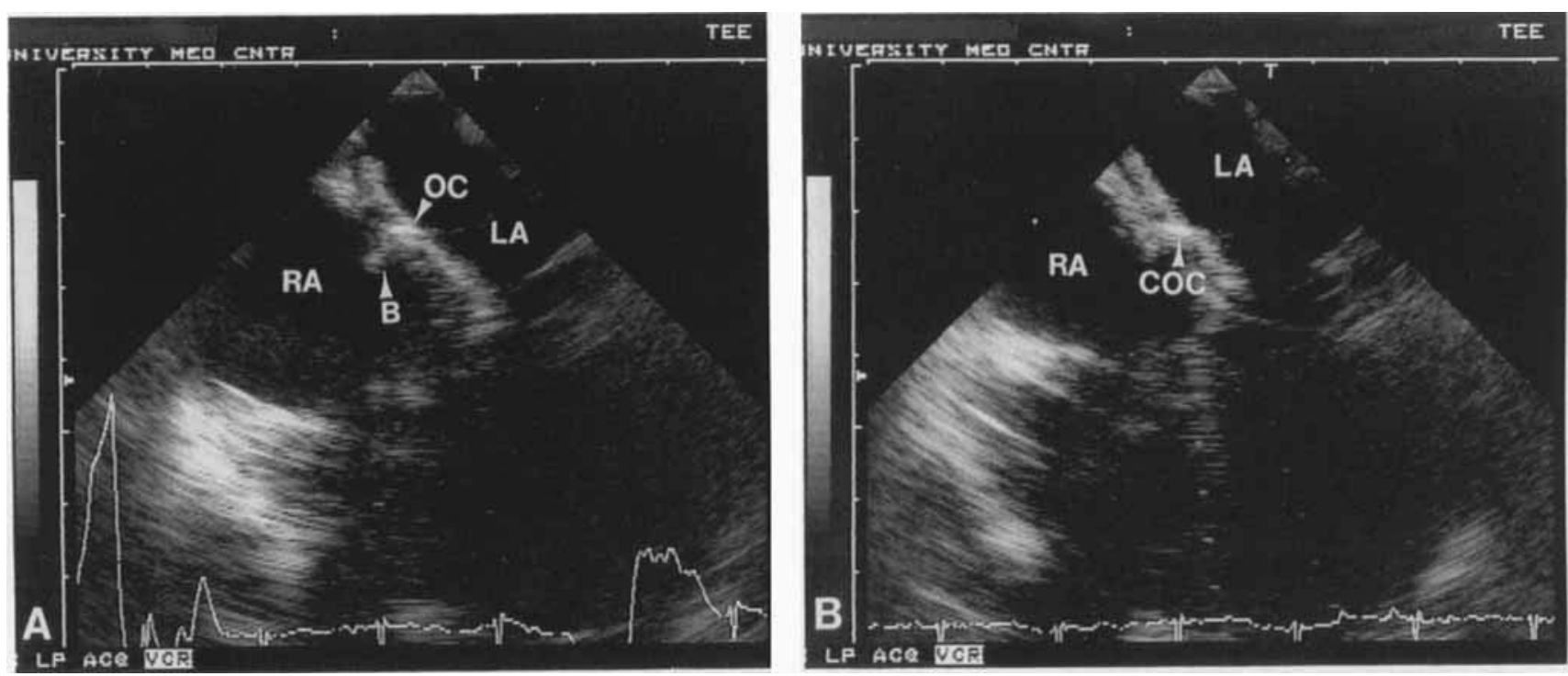

Fig. 3. Transesophageal echocardiographic images of the atrial septum. A: Correct deployment against the atrial septum of a $30 \mathrm{~mm}$ buttoned device occluder $(O C)$ is confirmed. The "button" (B) is noted. B: The small arrow points to the distal arm of the counteroccluder (COC) that was inadvertently directed across the ASD. RA = right atrium; LA = left atrium.

case was probably due to two factors: inadequate device size for defect size, and incorrect device position with one occluder arm passing through the septal defect. A 40 $\mathrm{mm}$ device is recommended for defects of $16-20 \mathrm{~mm}$ diameter, but at the original procedure it was thought that $35 \mathrm{~mm}$ was the largest size that could be accepted into the left atrium without impingement on the mitral valve or pulmonary veins. Placement of the device with an occluder arm in the right atrium is not uncommon, occurring in about half of the cases implanted under transthoracic echocardiographic guidance [8]. Proper device position is more readily achieved with transesophageal echocardiographic guidance [8]. Misplacement of the counteroccluder, as observed with the first attempt to button the $30 \mathrm{~mm}$ device in this patient, occurs when the end of the delivery sheath is far enough into the right atrium that the distal end of the counteroccluder is directed across the ASD before the proximal end is advanced out of the sheath. The weak radio-opacity of the delivery sheath and the multiple other radio-opaque structures (transesophageal probe, occluder skeleton, delivery wire, monitoring catheters) in the area where the counteroccluder is delivered may contribute to occurrence of this problem. Use of transseptal sheaths with distal radio-opaque markers (developed for radio frequency ablation procedures) and left anterior oblique views, which separate the counteroccluder delivery site from potentially distracting images may reduce the likelihood of counteroccluder misplacement. Fortunately, the fourth-generation buttoned device includes two but-

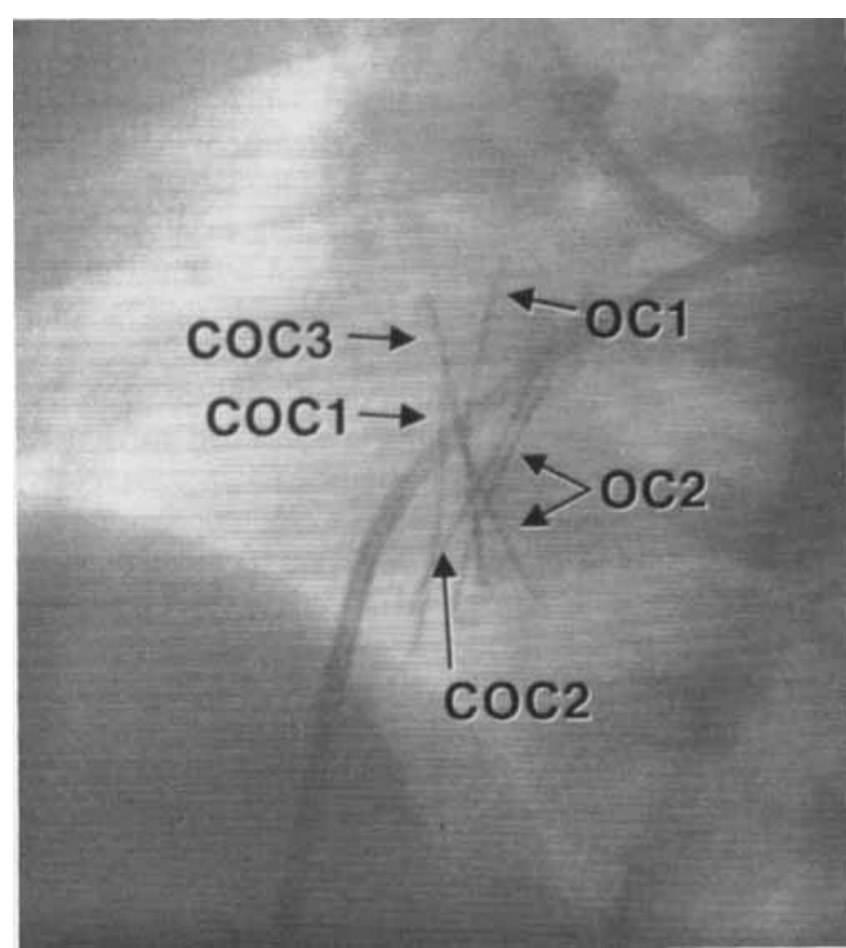

Fig. 4. Six segments of wire skeleton can be seen radiographically after release of the device: three on the left atrial side of the septum (one remaining in the original occluder [OC1] and two in the new occluder [OC2]), two on the right atrial side (the original counteroccluder [COC1] and the second new counteroccluder [COC3]), and one obliquely crossing the ASD (the first new counteroccluder [COC2]). 

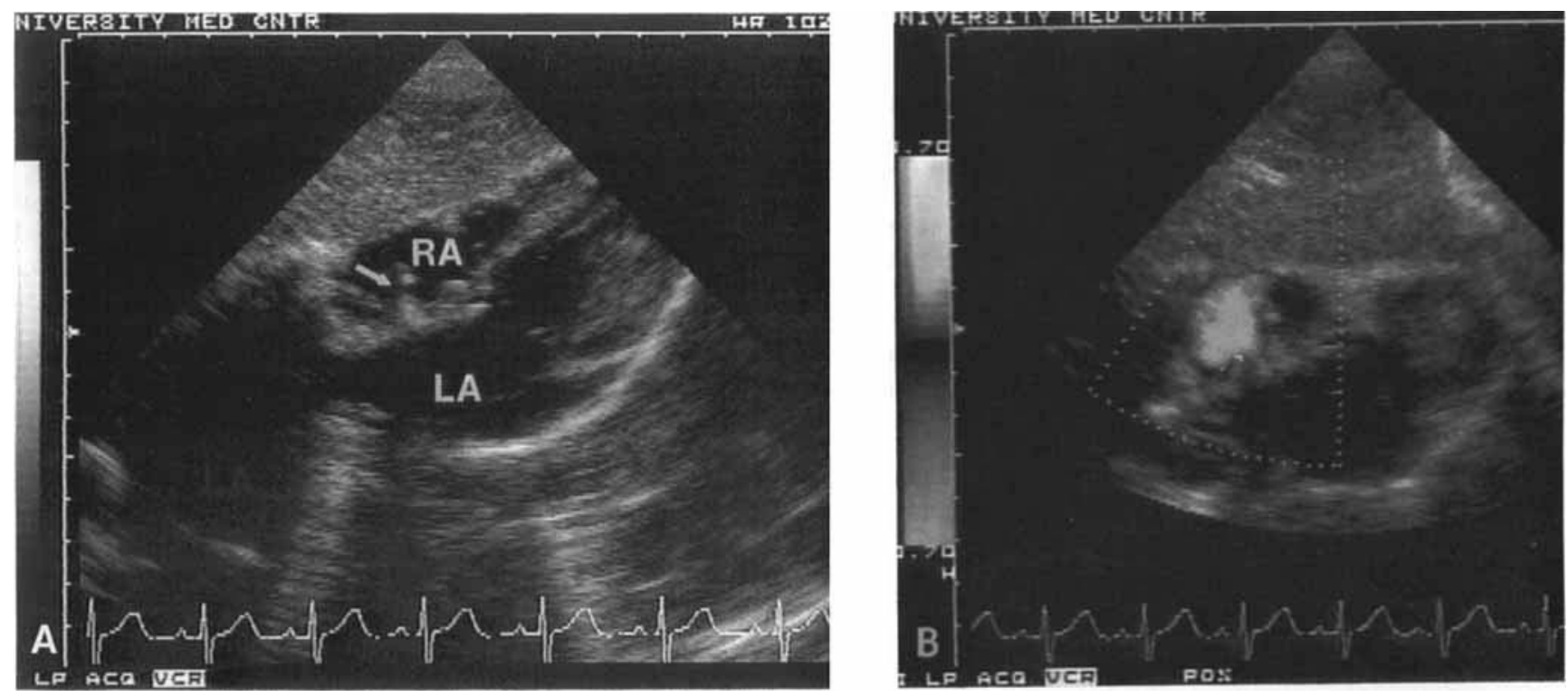

Fig. 5. Subcostal noninverted echocardiographic image of the atrlal septum at two months follow-up. A: The arrow points to the malpositioned arm of second new counteroccluder (COC2 from figure 4). B: With color flow Doppler interrogation there is no evidence of a residual shunt.

tons in series, as in the buttoned device for patent ductus arteriosus [9], while retaining the concentric radioopaque button design of the third generation buttoned device [3]. The additional button allowed placement of a second counteroccluder with confidence. We thought that this approach was safer than trying to retrieve the misplaced counteroccluder, since the risks of retrieving the newly placed occluder along with it was high.

Residual ASD after buttoned device implantation was successfully treated in this patient by placement of a second buttoned device after partial retrieval of the original device. We would have preferred to retrieve the entire original device, because placement of a second buttoned device, especially with two counteroccluders, substantially increased the amount of foreign material in this child's heart, which may increase the risk for thrombotic or thromboembolic complications. We plan to treat this patient with aspirin $(81 \mathrm{mg} /$ day $)$ for at least 6 months, as opposed to the 6-12 weeks usually recommended. At least partial device retrieval was necessary in this patient because the arm projecting into the left atrial cavity would have interfered with proper positioning of the second device. We suspect that perforation of the right atrium or inferior vena cava could occur during snare retrieval of the buttoned device unless a long sheath is used to prevent the force applied to the snare from being transmitted along the device arm to the endocardium or vascular wall. Embolization of some portions of the device, i.e., polyurethane foam, spring wire, or suture material during the retrieval process could have been a potential complication. We believe the device came apart as it did because of the through tissue ingrowth and endothelial coverage.

Our experience with this case has increased our confidence that the buttoned device will heal in a secure and nonthrombogenic manner into the atrial septum. The difficulties we encountered with repositioning and retrieving the device indicate that the device is firmly attached to the atrial septum at its points of apposition, and inspection of the foam portion of the retrieved occluder arm also demonstrates thorough tissue ingrowth and endothelial coverage of the device (Fig. 2). Although clearly it is best to prevent significant residual shunting by accurate application of an appropriate size occlusion device, the method described for occlusion of residual shunts with a second buttoned device may be helpful for those patients with residual ASDs who do not elect to undergo surgical device retrieval and defect closure.

\section{REFERENCES}

1. Boutin C, Musewe NN. Smallhorn JF. Dyck JD, Kobayashi T, Benson LN: Echocardiographic follow up of atrial septal defect after catheter closure by double-umbrella device. Circulation 88 : 621-627, 1993.

2. Lloyd TR, Rao PS, Beekman RH, Mendelsohn AM, Sideris EB: Atrial septal defect occlusion with the buttoned device (a multiinstitutional U.S. trial). Am J Cardiol 73:286-291, 1994.

3. Rao PS, Sideris EB, Hausdorf G, Rey C, Lloyd TR, Beekman RH. Worms AM, Bourlon F, Onorato E. Khallilullah M, Haddad J: International experience with secundum atrial septal defect oc- 
clusion by the buttoned device. Am Heart J 128:1022-1035, 1994.

4. Hosking MCK, Benson LN, Musewe N, Dyck JD, Freedom RM: Transcatheter occlusion of the persistently patent ductus arteriosus: Forty-month follow-up and prevalence of residual shunting. Circulation 84:2313-2317, 1991.

5. Hijazi ZM, Geggel RL: Results of anterograde transcatheter closure of patent ductus arteriosus using single or multiple Gianturco coils. Am J Cardiol 74:925-929, 1994.

6. Rao PS, Langhough R, Beekman RH, Lloyd TR, Sideris EB: Echocardiographic estimation of balloon-stretched diameter of secundum atrial septal defect for transcatheter occlusion. Am Heart J 124:172-175, 1992.
7. Arabia FA, Rosado LJ, Lloyd TR, Sethi GK: Management of complications of Sideris transcatheter devices for atrial septal defect closure. J Thorac Cardiovasc Surg 106:886-888, 1993.

8. Lloyd TR, Vermilion RP, Zamora R, Ludomirsky A, Beekman RH: Influence of echocardiographic guidance on positioning of the buttoned occluder for transcatheter closure of atrial septal defects. Echocardiography 1995 (in press).

9. Rao PS, Sideris EB, Haddad J, Rey C, Hausdorf G, Wilson AD, Smith PA, Chopra PS: Transcatheter occlusion of patent ductus arteriosus with adjustable buttoned device: Initial clinical experience. Circulation 88:1119-1126, 1993. 